\title{
ENSINO DE HISTÓRIA E DESENVOLVIMENTO DO PENSAMENTO HISTÓRICO NOS ANOS INICIAIS DO ENSINO FUNDAMENTAL
}

\author{
HISTORY TEACHING AND DEVELOPMENT OF HISTORICAL THINKING IN THE \\ INITIAL YEARS OF FUNDAMENTAL EDUCATION
}

\author{
Eleta de Carvalho Freire ${ }^{1}$ \\ Dayse Kassia da Silva Amorim² \\ Laís Almeida de Sousa ${ }^{3}$
}

\begin{abstract}
RESUMO: A pesquisa cujos resultados são apresentados neste artigo teve como objetivo conhecer a apropriação que estudantes do $5^{\circ}$ ano do ensino fundamental de uma escola da rede pública municipal na cidade do Jaboatão dos Guararapes, situada na Região Metropolitana do Recife em Pernambuco têm sobre as noções de temporalidade histórica. A investigação contou com apoio de pesquisas que discutem a relevância da articulação entre o desenvolvimento do pensamento histórico da criança e o ensino dos conhecimentos históricos. Foi desenvolvida por meio de observações de aulas, entrevista com a professora e vivência de uma atividade com os estudantes. Os dados foram analisados a partir dos referenciais da análise temática, propostos por Bardin (1977). Os resultados apontaram que os estudantes compreendem o tempo apoiando-se em sua dimensão cronológica e linear e que a sequenciação de fatos depende da presença de elementos concretos, apresentados de forma ordenada. A construção das noções de simultaneidade circunscreve-se a acontecimentos do tempo presente, mas não abarcam eventos do passado, e o entendimento sobre a temporalidade histórica estaria em fase inicial de sua construção, em razão da predominância da dimensão cronológica na compreensão da noção de tempo.
\end{abstract}

Palavras-Chave: Ensino de história. Temporalidade histórica. Desenvolvimento do pensamento histórico.

\begin{abstract}
The research whose results are presented in this article aimed to know the appropriation that students of the 5th year of elementary school of a public school in the city of Jaboatão dos Guararapes, located in the Metropolitan Region of Recife in Pernambuco have on the notions of temporality historical. The investigation was supported by research that discuss the relevance of the articulation between the development of the child's historical thought and the teaching of historical knowledge. It was developed through classroom observations, interviews with the teacher and an activity with students. The data were analyzed using the thematic analysis references, proposed by Bardin (1977). The results showed that students understand time based on its chronological and linear dimension and that the sequencing of facts depends on the presence of concrete elements, presented in an orderly manner. The construction of notions of simultaneity is limited to events in the present time, not encompassing events from the past, and the understanding of historical temporality would be in the initial phase of its construction, due to the predominance of the chronological dimension in understanding the notion of time.
\end{abstract}

Keywords: History teaching. Historical temporality. Development of historical thinking.

\footnotetext{
1 Doutora em Educação. Professora da Universidade Federal de Pernambuco.

2 Pedagoga, estudante da Universidade Federal de Pernambuco.

3 Pedagoga, estudante da Universidade Federal de Pernambuco.
} 


\section{Introdução}

Este artigo resulta de uma pesquisa que teve como objetivo investigar a compreensão que estudantes de uma turma do $5^{\circ}$ ano do ensino fundamental têm a respeito das noções de temporalidade histórica. A investigação parte da consideração de que a relevância do ensino das noções de tempo nos anos iniciais tem sido objeto de inquietações entre professores e professoras de história há algum tempo; que pesquisas realizadas nas últimas duas décadas têm apontado a necessidade de desenvolvimento do pensamento histórico das crianças desde os primeiros anos da escolaridade, e que as noções de tempo integram os conteúdos de ensino de propostas curriculares para essa etapa de ensino (BRASIL, 1997; PERNAMBUCO, 2013; RECIFE, 2015).

De acordo com professores e professoras de história dos anos finais do ensino fundamental, o processo de aquisição das noções de tempo tem se configurado como um dos principais desafios para o ensino e a aprendizagem dos conteúdos da disciplina. Isso porque as crianças ao chegarem à segunda fase da escolaridade fundamental ainda apresentam dificuldades de compreensão sobre a periodização histórica, sobre o estabelecimento de relações entre acontecimentos de diferentes períodos e, principalmente, sobre as relações entre presente e passado.

Embora seja parte integrante da vida das crianças desde muito cedo, uma vez que organiza suas rotinas e acompanha as transformações em suas vivências, as aprendizagens sobre o tempo envolvem certo grau de complexidade. Dessa complexidade decorre que, para se referirem ao tempo, os pequenos recorram a episódios mais imediatos de suas experiências, fazendo com que o tempo se confunda com elementos significativos como uma brincadeira, a chegada de alguém esperado, a hora de passear.

Essas rotinas proporcionam a construção das noções de anterioridade e posterioridade, de sequenciação dos acontecimentos e, posteriormente, de percepção do tempo, fazendo com que a criança passe da fase do tempo vivido, caracterizada pela ausência de consciência do tempo, para a etapa do tempo 
percebido, quando já abstrai relações temporais. Nesse sentido, Scaldaferri (2008, p. 53) afirma que:

\begin{abstract}
A noção do tempo histórico social, aquele que as sociedades humanas imprimem à época em que vivem, relacionando-o com o seu passado e o seu futuro, um tempo de simultaneidade de mudanças e permanências, é por demais abstrato e estranho à compreensão infantil.
\end{abstract}

No entanto, o nível de abstração envolvido nas aprendizagens sobre o tempo não quer dizer que essas aprendizagens não sejam acessíveis às crianças pequenas. Significa reconhecer que não se trata de algo natural, mas de um conhecimento construído socialmente que deve ser ensinado, e que a escola tem papel fundamental nessas aprendizagens.

Nesse sentido, pensar sobre o ensino de história desde os anos iniciais implica compreender que sua aprendizagem está apoiada no entendimento dos estudantes de que as ações humanas estão situadas no tempo e por esta razão são históricas. Não seria o caso de ensinar sobre os acontecimentos como se esses por si só respondessem pela aprendizagem histórica, mas de considerar que a historicidade dos acontecimentos está vinculada à temporalidade; que a aprendizagem significativa de um conteúdo depende de levarmos em conta as ideias históricas que o estudante já detém. Ou seja, considerar seu conhecimento sobre o tempo, o espaço e a história. Os saberes históricos nesse caso se configuram como uma dimensão do conhecimento que se articula com outras problemáticas da vida social. Abarcam aspectos que privilegiam a dimensão histórica do fazer humano e revelam a importância de seu ensino desde os primeiros anos da escolaridade.

Por outro lado, precisamos anotar que nas últimas décadas tornou-se crescente o número de pesquisas voltadas para o campo do ensino de história e, particularmente, para o ensino da disciplina nos anos iniciais do ensino fundamental, como afirmam Silva e Fonseca (2010). As descobertas dessas pesquisas dão a conhecer, entre outros aspectos, as razões pelas quais o ensino de história não se reduz à repetição e reprodução de memórias passadas, sem articulação com as memórias dos próprios estudantes. Nesse sentido, os autores afirmam que: 
Cresceu a pesquisa científica cujo objetivo de estudo é o ensino e a aprendizagem de História; passou-se a valorizar, cada vez mais, a cultura escolar, os saberes e as práticas educativas, desenvolvidos em diferentes lugares por docentes e outros atores do processo educativo. Essa foi uma conquista importante porque reafirmou, entre nós, a concepção de que ensinar História não é apenas repetir, reproduzir conhecimentos eruditos produzidos noutros espaços: existe também uma produção escolar (SILVA; FONSECA, 2010, p. 14).

No entanto, durante algum tempo o ensino dos conhecimentos históricos nos primeiros anos da escolaridade foi alvo de dúvidas referentes à capacidade de abstração das crianças para aprenderem sobre o tempo, o espaço e a(s) cultura(s) que, mediadas pelas relações sociais, vão tecendo mudanças e permanências que anunciam marcas do tempo nas semelhanças e diferenças entre passado e presente.

$\mathrm{Na}$ contracorrente desse pensamento, no campo da chamada educação histórica, Cooper (2006), na Inglaterra; Cainelli (2006) e Oliveira (2005), ambas no Brasil, entre outros, demonstraram através de suas pesquisas que as crianças nos anos iniciais da escolaridade não só aprendem sobre as relações entre presente e passado, como são capazes de sequenciar imagens, formular narrativas, fazer inferências sobre fontes, levantar hipóteses e estabelecer deduções. Para isso, no entanto, o ensino de história precisa estar ancorado na articulação entre o desenvolvimento do pensamento histórico da criança e o ensino dos conhecimentos históricos.

Para Cooper (2006), as crianças são capazes de desenvolver argumentos e produzir inferências sobre fontes históricas se forem ensinadas sobre como fazêlo. A autora entende que um bom começo para esse ensino seria ajudar as crianças a refletirem sobre o tempo a partir das mudanças em sua própria história de vida. Para isso, os estudantes deveriam ser provocados a contar histórias, narrar acontecimentos aos quais atribuem significado para relacionarem tais acontecimentos ao tempo passado e fazerem uso da linguagem do tempo.

Nessa direção, Abud (2004, p. 19) afirma que a aprendizagem dos conhecimentos históricos tem como "objetivo situar o aluno no momento histórico em que vive". Entretanto, algumas práticas desenvolvidas nas escolas 
apoiam-se na crença de que datar fatos é suficiente para que os estudantes consigam se localizar temporalmente. Com base nessa compreensão, exige-se que os estudantes memorizem datas referentes a acontecimentos históricos, entretanto, segundo a autora, situar-se historicamente é compreender que os acontecimentos que surgem a sua volta fluem de uma dinâmica de relações próximas e distantes que se estabelecem numa variedade temporal.

Por sua vez, Siman (2005), embora esteja em outro campo de investigação, também argumenta que a compreensão sobre o tempo permite ao estudante estabelecer relações entre fatos do passado e acontecimentos vividos no presente; oportuniza reconhecer que no tempo histórico há coexistência de diferentes tempos - passado, presente e futuro - ocupando simultaneamente diferentes espaços. Favorece o entendimento de que o tempo vivido tem ritmos e durações próprias, porque pensar historicamente supõe a capacidade de identificar mudanças e permanências, diferenças e semelhanças entre passado, presente e futuro.

Assim, ao incluir as vivências cotidianas dos estudantes nas aulas de história, possibilitamos que estes passem a se localizar temporal e socialmente. Ou seja, as aprendizagens dos conhecimentos históricos envolvem necessariamente aprendizagens sobre o tempo e são necessárias à vida social, uma vez que o tempo opera como organizador dos vários aspectos da vida humana, entre os quais os estudantes podem reconhecer a organização temporal do cotidiano de suas famílias, da escola, do trabalho (BERGAMASCHI, 2000).

No entanto, na contracorrente do que apontam as pesquisas citadas, o ensino de história ainda convive na atualidade com os dilemas que lhe foram criados desde a sua inserção como disciplina nos currículos oficiais das escolas brasileiras no final do século XIX. Criada para atender aos objetivos de formação de uma identidade nacional com predominância de conteúdos relativos à história pátria e à constituição do povo brasileiro, o ensino de história acabou por se consolidar como um ensino voltado às questões políticas, apoiado em fatos isolados, cuja aprendizagem não representava o desenvolvimento do pensamento histórico dos/as estudantes.

Não obstante as mudanças observadas nas formas de pensar o ensino de história, a partir da segunda metade do século $X X$ e, principalmente, após Lei 
9394/96, que estabelece as Diretrizes e Bases da Educação Nacional (LDB), o ensino de história ainda convive com resquícios de um passado marcado por práticas de transmissão, memorização e reprodução de conteúdos.

Por outro lado, o retorno do ensino de história aos currículos dos anos iniciais do ensino fundamental definido pela LDB, se fez presente na edição dos Parâmetros Curriculares Nacionais (BRASIL, 1997), que orientou à época, a elaboração de propostas curriculares de estados e municípios, apontando como objetivos do ensino de história:

Identificar o próprio grupo de convívio e as relações que estabelecem com outros tempos e espaços; Organizar alguns repertórios histórico-culturais que lhes permitam localizar acontecimentos numa multiplicidade de tempo, de modo a formular explicações para algumas questões do presente e do passado; Reconhecer mudanças e permanências nas vivências humanas, presentes na sua realidade e em outras comunidades, próximas ou distantes no tempo e no espaço (BRASIL, 1997, p.33).

Com apoio em pesquisas mais recentes, que também apontam entre os conteúdos de história o ensino sobre relações temporais, nos Parâmetros para a Educação Básica do Estado de Pernambuco as dezenove expectativas de aprendizagem de história estão previstas para serem trabalhadas a partir dos anos iniciais. Entre elas destacamos:

\footnotetext{
Reconhecer e utilizar medidas de tempo, usadas pelos homens e mulheres, em seu cotidiano e, pelos historiadores em seus escritos (dia, mês, semana, ano, década, século, milênio, era) (EA-1); Analisar a relação entre diferentes maneiras de vivenciar, apreender, organizar, regular, representar o tempo cotidiano e diferentes contextos socioeconômicos e culturais (EA-9); Estabelecer relação entre o passado e o presente, por meio da percepção de continuidades, transformações, diferenças e semelhanças (EA-17) (PERNAMBUCO, 2013, p. 51-52).
}

De igual modo, o ensino e as aprendizagens sobre o tempo em sua dimensão quantitativa, mas também sociocultural estão previstos na Política de Ensino da Rede Municipal do Recife, expressas nos seguintes objetivos:

Reconhecer medidas convencionais de tempo, utilizadas pelas pessoas em seu cotidiano, em diferentes tempos e espaços, e na construção das narrativas; Identificar, a partir de fontes diversas, 
mudanças e permanências no Recife de ontem e de hoje; Estabelecer relações entre o tempo presente e o passado, a partir do estudo de fontes históricas diversas; Relacionar passado e presente, identificando mudanças e permanências entre períodos históricos (RECIFE, 2015, p. 230-234).

Com referência nos três elementos anteriormente apontados - inquietações de professores de história, pesquisas desenvolvidas nas últimas décadas e propostas curriculares de história - tivemos como campo empírico desta investigação uma escola pública do município de Jaboatão dos Guararapes, situada na Região Metropolitana do Recife em Pernambuco. Após o consentimento da gestão da escola e a anuência da docente de uma turma do $5^{\circ}$ ano, observamos aulas de história durante vinte horas, realizamos uma entrevista semiestruturada com a professora e vivenciamos uma atividade com os dezoito estudantes da turma. Interessa-nos destacar que todo processo de coleta dos dados foi pautado pelo respeito e acompanhado dos cuidados devidos aos participantes da pesquisa. De igual modo, registramos a aceitação e o acolhimento às pesquisadoras em todo o período que estivemos na escola. Os dados foram analisados a partir dos referenciais da análise temática, propostos por Bardin (1977).

\section{A aprendizagem da temporalidade histórica}

O que já sabem as crianças sobre o tempo ao iniciarem o ensino fundamental? O que aprendem sobre o tempo fora da escola e como lidam com essas aprendizagens? De que forma arranjam suas vidas e percebem a organização da vida em família pautada pelo tempo? Será que compreendem o tempo como organizador de suas ações cotidianas e das ações sociais mais amplas? De que forma podemos ajudá-las a progredirem em suas aprendizagens sobre o tempo para melhor compreenderem a dinâmica da vida em sociedade? Talvez essas questões devessem fazer parte da nossa programação de ensino para os anos iniciais do ensino fundamental desde seu início, considerando que o entendimento sobre a temporalidade dos acontecimentos constitui fator basilar para compreensão da história. 
Segundo Cooper (2006), para as crianças pequenas o tempo se apresenta como natural, parece fazer parte da natureza como outros elementos que nela existem. Isso porque, a criança vive o tempo, mas ainda não abstrai sua existência, ou a forma como o tempo funciona na organização da vida cotidiana. $\mathrm{Na}$ escola a uniformidade temporal traz a marca das rotinas que são construídas e que favorecem a compreensão das crianças sobre relações de ordenação e duração dos acontecimentos breves. Mas, e em relação à vida coletiva, como promover a progressão das aprendizagens das crianças sobre o tempo?

Inicialmente parece necessário considerar que nos primeiros anos do ensino fundamental os estudantes conseguem compreender relações temporais ordenação, duração e simultaneidade - necessárias à construção do conceito de tempo histórico. No entanto, por se tratar de aprendizagens complexas, precisamos levar em conta que as noções de tempo são apropriadas de forma gradual e relativamente lenta. Trata-se de um processo que não diz respeito apenas a vivência das rotinas escolares, embora estas representem importantes elementos para iniciar experiências didáticas de aprendizagem sobre tais noções e conceitos, de forma dialogada com as vivências cotidianas dos estudantes.

Assim, a compreensão sobre ordem ou sucessão favorece o desenvolvimento da ideia de cronologia que contribui para o entendimento sobre o tempo histórico, no entanto representa apenas uma de suas dimensões. Embora necessária à percepção sobre a historicidade dos acontecimentos, a cronologia constitui a ordenação de fatos em uma sequência linear. A apreensão do tempo histórico, porém, requer o entendimento de outras relações, sobretudo da dimensão social presente no tempo da ação humana.

Do mesmo modo, além de assimilar acontecimentos a partir da identificação de uma sequência que aponta o que aconteceu antes e depois, o estudante deverá ser provocado, desde os anos iniciais da escolaridade a avançar no sentido de perceber a duração dos eventos. Carece de aprender que a duração representa o intervalo de tempo em que um acontecimento se processa e, a exemplo da cronologia, também pode ser calculada e quantificada. Ademais, essa aprendizagem abrange o discernimento de que esse intervalo nem sempre é uniforme, podendo variar de acordo com os ritmos das ações de pessoas e grupos. Outra relação temporal essencial para a compreensão de que o tempo é 
uma construção histórica e cultural é a simultaneidade. Esta implica a capacidade de perceber que dois acontecimentos podem acontecer ao mesmo tempo - no presente ou no passado - em diferentes espaços, próximos ou distantes.

A aprendizagem dessas noções é importante para que o estudante consiga perceber o tempo como um continuum, possa datar acontecimentos, quantificar sua duração, calcular a velocidade das mudanças e das permanências, relacionar presente, passado e futuro. Contudo, tais noções não são suficientes para a compreensão sobre a temporalidade histórica, cujo entendimento excede o domínio das medidas do tempo e abarca a atribuição de sentido que envolve sensibilidade, afetividade, imaginação.

Desse modo, considerando que o tempo não é marcado por acontecimentos isolados, mas dimensionado pelas transformações que as pessoas e grupos realizam em seu espaço social, ao ensinar história, precisamos considerar que o tempo caracteriza-se como uma invenção humana, uma convenção social. Como afirma Bergamaschi (2000, p. 4), trata-se de "uma construção sociocultural, que se apresenta de distintas formas na sociedade desde épocas remotas e que modula a vida das pessoas de diferentes maneiras".

Se o tempo possui uma dimensão sociocultural, podemos inferir que as pessoas através de suas ações organizam novas e diferentes maneiras de viver, pois a temporalidade histórica possui uma relação com o tempo vivido, com sua duração e ritmos próprios. Nesse sentido, o tempo histórico é um tempo múltiplo, abarca outros tempos. E sua compreensão apoia-se em elementos da subjetividade dos estudantes, depende de uma sensibilidade que favoreça a percepção dos sinais das transformações ocorridas, gerando novos sentidos para a história.

Por esta razão, a aprendizagem sobre a temporalidade histórica envolve a identificação do estudante com sua própria historicidade. Ao sentir-se inserido na história a partir das memórias individuais de sua existência, de sua família e de outros grupos de convívio, as crianças atribuem sentido às aprendizagens sobre o tempo e estará desenvolvendo o pensamento histórico.

Essa tomada de consciência possibilita perceber alterações em outros grupos e essa percepção favorece o entendimento de que a apropriação e a utilização do tempo são culturais, que a maneira como os grupos se organizam e 
se transformam é diversa, pois a forma de viver das pessoas e dos grupos resulta de diferentes relações. Isso porque o tempo possui uma representação simbólica no espaço, construída e mediada pelas relações sociais.

Assim, o estudante compreenderá que diferentes sociedades vivenciam acontecimentos - políticos, econômicos, culturais - que são tecidos no interior dos grupos e que podem ser percebidos a partir do estudo do que acontece em sua própria realidade social. Essas aprendizagens possibilitam compreender o tempo como construção social que abarca mudanças e permanências; continuidades, descontinuidades e rupturas; permitem perceber diferenças entre espaços, tempos e épocas; compreender outras sociedades atuais próximas e distantes, e também aquelas que existiram no passado.

Como afirma Siman (2005, p. 118) "a história, que faz do tempo a sua figura central, opera transformações no tempo vivido, cujos registros e traços são encontrados na memória individual e coletiva". Assim, ao pensar historicamente o estudante supõe identificar uma relação de ruptura entre o presente, o passado e o futuro, desenvolve a capacidade de identificar a simultaneidade dos acontecimentos da vida social em diferentes contextos. Contudo, "no plano de desenvolvimento cognitivo, o entendimento da relação entre o tempo vivido e o tempo histórico, ou da relação entre a memória individual e coletiva se dá de forma lenta e linear" (SIMAN, 2005, p. 120).

Nessa direção, entendemos que se os anos iniciais da escolaridade fundamental constituem o período propício para construção das noções básicas necessárias à aprendizagem da história, precisamos considerar que as noções de tempo estão na base da formação do pensamento histórico. Ancoram a percepção da existência de diferentes ritmos e épocas, e a compreensão de que o tempo revela transformações sociais, mas também permanências entre modos de vida, organização do espaço e vida em sociedade.

\section{Entre a escuta e a observação: o que revelam as aulas de história?}

A realização da pesquisa se deu em uma turma de $5^{\circ}$ ano por entendermos que nessa fase da escolaridade a compreensão das crianças sobre o tempo já não depende de referência direta ao acontecimento imediato, ou seja, ao tempo vivido. De igual modo, inferimos que os estudantes teriam vivenciado 
experiências de aprendizagem sobre o tempo nos anos anteriores e estariam na transição entre a percepção e a concepção do tempo.

As observações das aulas de história tomaram como objetos de análise as metodologias de ensino adotadas pela professora da turma, os recursos didáticos utilizados nas aulas e as formas de interação dos estudantes entre si e destes com a docente.

No que concerne às metodologias de ensino observamos variações discretas nas aulas que, em geral, envolviam a leitura coletiva de um capítulo do livro didático e a realização de atividades do próprio livro. Em uma dessas leituras, o livro Pernambuco e muitas Histórias: história do estado de Pernambuco 4 tratava sobre povos indígenas. Além da leitura, a professora solicitou que os estudantes localizassem os nomes das tribos de Pernambuco em um mapa do próprio livro e lançou algumas perguntas sobre a identificação de características físicas e ações dos indígenas apresentadas nas imagens. As perguntas, contudo, não envolviam a problematização do conteúdo, nem faziam menção à temporalidade histórica representada, aos diferentes modos de vida das populações indígenas ou às mudanças e permanências observadas em através do tempo.

A leitura do texto didático apenas constatava a presença indígena no Estado, sem registro ou problematização sobre as relações sociais inerentes aos processos históricos. No entanto, como afirma Freitas (2010, p. 160) "os indígenas são sujeitos da experiência brasileira. Já estavam por aqui quando os portugueses desembarcaram no século XVI". Para o autor, "o problema é que esse papel de sujeito da história, no passado distante e no presente recente da história do Brasil não vem sendo devidamente reconhecido pelos historiadores e professores de História ao longo do período republicano" (FREITAS, 2010, p.160161).

Por outro lado, observamos que as aulas de história eram guiadas pelo livro didático que, como afirma Fonseca (2003, p. 50), assumiu "a forma do currículo e do saber na escola", embora devesse ser um entre outros artefatos culturais que podem contribuir para o ensino e a aprendizagem dos conhecimentos históricos. Isso porque, ainda que necessário, o livro didático de modo geral não

4Os livros adotados pela escola eram: Vesentini, Martins e Pécora ([2011]) e Cavalcanti ([2011]). 
apresenta elementos que estimulem a participação dos estudantes nas atividades, provoquem sua curiosidade, ou promovam o debate.

Nesse sentido, algumas questões levantadas pelos estudantes durante as aulas se destacaram, tal como, quando um deles perguntou: - "professora, 12 mil anos é pouco tempo?" E a professora respondeu: - "não, 12 mil anos não é pouco tempo". Diante da indagação envolvendo a mensuração do tempo nos perguntamos, se a resposta tivesse incluído uma comparação com o tempo de existência do município ou do país, por exemplo, não teria favorecido a compreensão dos estudantes sobre a dimensão temporal? Isso porque, entendemos que a aprendizagem dos conhecimentos históricos, assim como "o processo de investigação histórica envolve a compreensão de conceitos do tempo: a mensuração do tempo, as continuidades e mudanças, as causas e efeitos de eventos e de mudanças ao longo do tempo, semelhanças e diferenças entre períodos", como defende Cooper (2006, p. 175).

A situação analisada nos leva a argumentar em favor de um planejamento de aula, cujos conteúdos, etapas e distribuição do tempo para as atividades, tenham como ponto de partida os conhecimentos que os estudantes detêm e a previsão de possíveis questões a serem por eles levantadas. Nesse sentido, Zamboni e Oliveira (2009, p. 125) defendem que:

o planejamento das atividades, através de anotações escritas, formas pelas quais, concretizamos nossa temporalidade, podem influenciar para a constituição de uma relação específica com o tempo na aprendizagem quanto à capacidade de planejamento e organização, porque estabelece uma diferenciação entre o tempo vivido.

Em outra aula, o assunto abordado - a Inconfidência Mineira - seguiu a mesma metodologia da aula anterior. Na ocasião, os estudantes demonstraram dificuldades de concentração tanto durante a leitura como na realização da atividade, talvez em razão do distanciamento temporal do período tratado ou da ausência de uma contextualização que os aproximasse do entendimento sobre o espaço e o tempo histórico a partir de situações análogas. A aula nos levou a concordar com Corrêa (2005, p. 3), quando afirma que "o tempo pode ser organizado e analisado, para efeito de estudo sob diferentes enfoques". Dentre esses enfoques podemos destacar: a) o tempo vivido, do qual fazem parte os 
indivíduos e suas experiências concretas vivenciadas em cada momento; b) o tempo percebido que se refere a uma reconstrução dos acontecimentos históricos a partir de referências na própria historicidade e c) o tempo refletido, concebido, que envolve uma mediação entre o tempo presente e as memórias das dimensões temporais que devem ser resgatadas.

$\mathrm{Na}$ aula seguinte a professora tratou sobre o dia do trabalhador, a partir de estratégia metodológica mais participativa e sem uso do livro didático. Lembrou aos estudantes que havia solicitado para aquele dia uma roupa que representasse uma profissão, porém apenas uma estudante levou um jaleco para representar a profissão de médica. A professora indagou sobre a importância da profissão e o que ela representa para a sociedade. A estudante respondeu que ser médica é uma profissão muito importante, porque os médicos podem curar as pessoas quando elas estão doentes e os demais estudantes participaram da apresentação da colega. Nessa aula, embora o tema fosse o dia do trabalhador, não houve nenhuma discussão sobre o conceito de trabalho no tempo presente ou em outros tempos, sobre as mudanças nas formas e relações de trabalho ao longo do tempo, sobre diferentes profissões ou ainda sobre direitos e deveres do trabalhador. Nesse sentido, considerando que acontecimentos e objetos existentes no mundo mudam com o tempo e que elementos que existem hoje, necessariamente não existiram no passado ou existirão no futuro, entendemos que para os estudantes do ensino fundamental essa discussão seria crucial tanto para a aprendizagem sobre o conceito de trabalho, como para o desenvolvimento do pensamento histórico. Isso porque concordamos com Miranda (2010, p. 372) quando afirma que "pensar os processos educativos em relação à História implica, grosso modo, educar a criança para compreender e lidar com dimensões do tempo que se revelam no entendimento da mudança".

Conversando entre si nesse dia, os estudantes discutiam sobre os dias dos meses, ou sobre a quantidade de dias de cada mês. Um estudante disse: - "as datas existem até o dia 31" e outro estudante respondeu: - "não são todos os meses que terminam em 31, há um mês que vai até o dia 28 ou 29". Essa conversa revelou que, por um lado, os estudantes ainda não haviam consolidado aprendizagens referentes ao tempo cronológico referente aos meses do ano, pois expressavam curiosidade e dúvidas em relação ao número de dias de cada mês e 
aos nomes dos meses do ano, uma vez que não citaram o nome do mês que tem 28 ou 29 dias. Por outro lado, a conversa mostrou também que os estudantes problematizam aspectos sobre a existência e contagem do tempo; refletem sobre o tempo e têm curiosidade de compreender formas de organização do tempo. Como afirma Cooper (2006), as crianças transferem seus aprendizados para as conversas nos seus grupos, fazem observações, deduções e sugestões sobre o desconhecido a partir das informações e conhecimentos que detêm.

Em mais uma aula observada o assunto dizia respeito ao dia a dia dos africanos escravizados no Brasil. Ao fazer a leitura, a professora explicou algumas questões sobre o cotidiano dos escravizados e sua rotina de trabalho. Destacou que essas pessoas trabalhavam quinze horas por dia, mas que aos domingos e feriados não costumavam trabalhar. A partir dessa fala, um estudante questionou dizendo: - "os escravos deviam trabalhar todos os dias, porque eles eram escravos". Em contraposição à seriedade da afirmação feita pelo estudante, que expressou uma compreensão bastante equivocada sobre a condição humana do escravizado, a professora encerrou a leitura e a explicação do assunto sem provocar nenhuma reflexão sobre essa fala. A esse respeito, Conceição (2010, p. 144) afirma que "abordar na escola, e em particular no ensino de História, a cultura afro-brasileira é de capital importância". Contudo, a autora considera essencial "nós professores nos apropriarmos de uma literatura de revisão desse aspecto, como requisito para as releituras que precisamos fazer ao abordar o assunto em sala de aula".

Desse modo, no que se refere às metodologias de ensino, as observações nos permitiram identificar necessidades de aprendizagem dos estudantes que parecem se ressentir da manutenção de um ensino de história pautado na transmissão de conteúdos, cujas marcas apontam para a necessidade de problematização e contextualização e para lacunas em relação a exemplos e comparações.

Em relação aos recursos didáticos, cabe anotar que a escola campo da pesquisa pertence a uma rede municipal de ensino e está situada em um bairro periférico da cidade, com isso afirmamos que tais recursos são escassos. No entanto, indagamos sobre os acervos das obras complementares - formados por obras literárias - disponibilizadas às redes públicas de ensino, além de outros 
materiais do Programa Nacional Biblioteca da Escola (PNBE), cuja distribuição apresentou certa regularidade na última década. Esse questionamento decorre do fato de termos observado na escola apenas livros didáticos e mapas.

Em que pese a escassez de recursos didáticos, há que se discutir também seu aproveitamento nas aulas. Em determinada ocasião, a professora, ao fazer uma anotação na lousa sobre o município de Jaboatão dos Guararapes, foi perguntada pelos estudantes em relação ao porquê do nome da cidade conter as palavras "dos Guararapes", a docente respondeu de forma evasiva e continuou a escrever sem atender à curiosidade das crianças. A gestora da escola - que passava em frente à sala durante a aula - informou à docente sobre a existência de um mapa do município que poderia ser utilizado naquela aula e o enviou para a sala. Contudo, a docente apenas o pendurou na parede e não faz uso do recurso didático.

Na ocasião, além de não fazer uso do mapa para explorar aspectos do município, a docente deixou de promover uma situação didática sobre as noções de tempo advinda da própria curiosidade dos estudantes. Isso porque o município quando elevado à categoria de Cidade em 1884 recebeu o nome de Jaboatão, mas passou a se chamar Jaboatão dos Guararapes, a partir de 1989, em homenagem aos Montes Guararapes, local da realização de batalhas históricas. Assim, a problematização e a contextualização da mudança do nome do município, além de atender à curiosidade dos estudantes, despertaria maior interesse para outras descobertas, por se tratar do município onde se localiza a escola e no qual residem as crianças, o que possivelmente suscitaria nelas o sentimento de pertencimento ao local.

Além disso, possibilitaria aos estudantes compreenderem que a história é uma construção aberta às transformações sociais e culturais, e que da mesma forma que o nome e a bandeira do município mudaram, outros elementos e aspectos sociais transformam-se com o tempo. Assim, se entendemos que cabe ao ensino de história, situar o estudante na construção do mundo e desenvolver seu sentimento de amor pela história da qual fazem parte, devemos concordar que, nessa direção, os conhecimentos históricos estariam contribuindo para uma formação crítica desse estudante. Nesse sentido, Zamboni e Fonseca (2010, p. 342) afirmam que: 
[...] consideramos pertinente introduzir a criança no "mundo formal" do conhecimento histórico: familiarizá-la com o uso de um vocabulário histórico; despertá-la para a importância das fontes e dos documentos e de conhecer noções, conceitos, suportes modos de construção do conhecimento histórico.

Embora não deixemos de reconhecer as dificuldades enfrentadas pela professora diante das condições de trabalho com uma turma de dezoito estudantes e com recursos escassos, as formas de interação entre os estudantes e destes com a docente não nos pareceram ser as mais favoráveis as aprendizagem sobre o tempo. Isso porque, além da complexidade e grau de abstração, envolvidos na construção das noções temporais, ora as crianças discutiam dúvidas entre si sem a mediação da docente, ora as dúvidas e questionamentos das crianças escapavam a uma problematização no decorrer da aula e não se transformavam em objeto de discussão e ensino.

\section{Ensino e aprendizagem dos conhecimentos históricos: o diálogo com a professora}

$\mathrm{Na}$ entrevista realizada com a professora abordamos aspectos que foram expressos em questões referentes: a) aos desafios de ensinar história nos anos iniciais; b) aos recursos e estratégias metodológicas utilizadas no ensino dos conhecimentos históricos; c) à abordagem do livro didático em relação ao conceito de tempo; d) aos conteúdos de ensino e às dificuldades de aprendizagem das crianças sobre o conceito de tempo.

De acordo com a docente, os estudantes apresentavam muita dificuldade para compreender os conteúdos de história e seus conceitos. Apontou como problema a dificuldade de compreensão sobre as relações temporais, ou seja, o entendimento sobre as relações entre passado e presente. No entanto, a docente destacou o desafio de "ensinar, explicar aos estudantes, com dificuldades de leitura e escrita. Mesmo que você leia e explique os fatos, a criança parece não compreender as relações temporais, as sociedades e os fatos estudados".

Nesse aspecto observamos certo distanciamento entre as aulas ministradas pela docente e sua fala, uma vez que nas aulas a necessidade de problematização e de exploração de questões levantadas pelos estudantes se fez 
notar, conduzindo-nos a algumas reflexões. Se os estudantes apresentavam dificuldades de compreensão sobre a relação entre passado e presente, não seria o caso de proporcionar mais situações de ensino sobre as relações temporais? Que estratégias de ensino poderiam ser adotadas para ajudar os estudantes a se apropriarem do conceito de tempo? Por que não ajudar os estudantes a superarem as dificuldades com a leitura a partir de textos da literatura infantil? Nesse sentido, Fonseca (2003, p. 167), destaca que "uma das possibilidades metodológicas interessantes é a literatura infantil. Várias obras literárias enfocam problemas sociais, ao mesmo tempo em que canções, fotografias, filmes acessíveis ao universo infanto-juvenil permitem ricas análises".

Em relação aos recursos e às estratégias metodológicas utilizadas, a professora corrobora o que havíamos observado. O uso do livro didático é frequente nas aulas de história e os conteúdos do livro vão estabelecendo a sequência dos conhecimentos ensinados. Ainda que a docente tenha afirmado utilizar "o próprio livro e a linha do tempo bem trabalhada com datas pessoais, fotos e pinturas do livro didático", nas práticas observadas registramos o uso do livro didático em todas as aulas. Como podemos observar no extrato de fala a seguir, a docente revela uma representação bastante positiva do livro didático ao declarar que este "aborda tudo claramente, e que traz explicações claras para os estudantes". A esse respeito, Fonseca (2003, p. 164) argumenta que precisamos reconhecer

não só a estreita ligação entre os saberes escolares e a vida social, mas também a necessidade de (re) construirmos nosso conceito de ensino e aprendizagem. As metodologias de ensino na atualidade exigem permanente atualização, constante investigação e contínua incorporação de diferentes fontes em sala de aula.

A respeito dos conteúdos de ensino de história a professora relata que "são vários os conteúdos, mas os temas de conteúdos africanos, as artes e a História de nosso Estado são considerados como sendo os mais importantes para o aprendizado dos alunos". Nesse aspecto sua fala também se revelou distante da organização de conteúdos observada durante a pesquisa quando vivenciamos aulas mais pautadas pelo livro didático que pelas necessidades de aprendizagem dos estudantes. Nesse sentido, Nemi e Martins (1996, p. 35) afirmam que a sala 
de aula é

[...] um espaço privilegiado para o debate, para a apropriação e sistematização dos conteúdos e experiências vividas no dia a dia. $O$ aluno poderá conhecer melhor o seu mundo questionando as informações que recebe de seu meio e realizando atividades, individuais e em grupo.

No que concerne às dificuldades enfrentadas pelos estudantes para a aprendizagem sobre o conceito de tempo, a professora afirma que "o estudante não consegue fazer relação temporal do passado com o presente". Não obstante, registramos momentos de inquietação dos estudantes em relação à contagem do tempo, datação e sequência de acontecimentos. Nesse sentido, concordamos com Miranda (2010) quando afirma que, ao chegar à escola, o estudante traz uma bagagem de experiências de natureza diversa que, grosso modo, se converte em memória capaz de justificar e constituir hábitos e atitudes que se repetem. Isso quer dizer que a aprendizagem sobre a temporalidade histórica não se dá apenas no espaço escolar, mas no convívio com a família e a comunidade; em contato com os meios de comunicação e com as narrativas presentes no cotidiano. No entanto, é na escola que este começa a lidar de forma sistematizada com medidores temporais, como horas, semanas, meses e anos, isto é, passa a operar formalmente com o tempo cronológico que possibilita ao estudante situar-se temporalmente pela datação, cronologia e periodização como dimensões do tempo social e favorece a aprendizagem sobre o tempo histórico.

\section{As aprendizagens sobre a temporalidade histórica revelada pelos estudantes}

$\mathrm{Na}$ terceira fase da pesquisa, após acordo com a professora e com as crianças, realizamos uma atividade com os dezoito estudantes da turma objetivando apreender a compreensão que as crianças já haviam construído sobre a historicidade do tempo. Na atividade foram apresentadas três imagens sobre as quais fizemos algumas indagações relativas às noções de ordenação e simultaneidade, reconhecimento de semelhanças e diferenças, observadas entre espaços e tempos. 
Além das indagações pautadas nas imagens, apresentamos duas questões referenciadas em acontecimentos da vida cotidiana dos estudantes, por meio das quais verificamos quais aprendizagens demonstravam em relação às noções de cronologia e simultaneidade com base em acontecimentos da vida familiar. Por fim, duas perguntas, relacionadas a dados históricos do município, diziam respeito à relação entre passado e presente.

Inicialmente foram apresentadas três imagens para que os estudantes identificassem se eram representativas de um mesmo espaço e/ou de um mesmo tempo. As imagens retratavam espaços diferentes e tempos diversos, tendo em comum apenas a edificação da sede da prefeitura do município, escolhida em razão das marcantes diferenças apresentadas nos vários tempos e da proposição para elaboração de uma sequência.

Imagem 1 - Prédio da Prefeitura (1992)

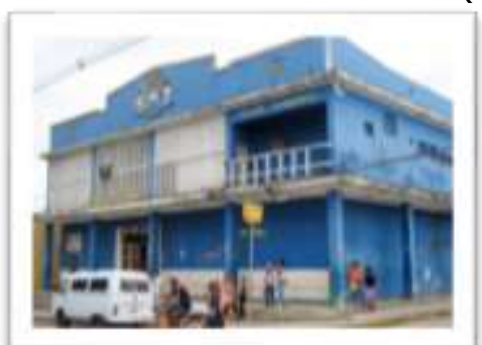

Fonte: Leonir Ângelo Lunardi, Antigo Prédio da Prefeitura de Jaboatão dos Guararapes - PE. s/d.

Imagem 3 - Prédio da Prefeitura (2015)

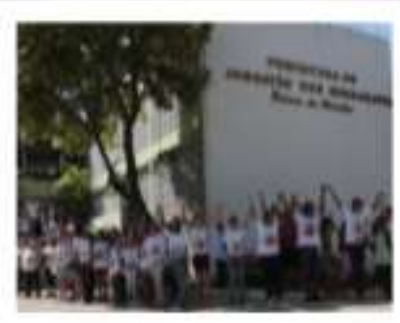

Fonte: Arthur Mota, Prefeitura de Jaboatão, 2017.
Imagem > - Prédin da Prefeitura (1932)

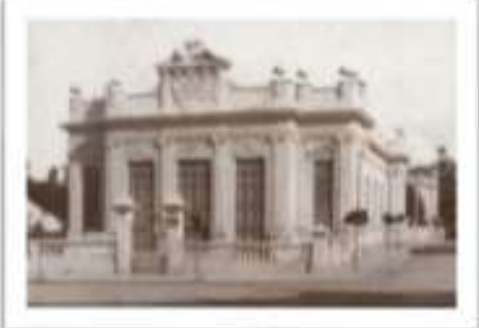

Fonte: Van-hoeven Ferreira Veloso, Paço Municipal, 1991.

Ao serem indagados se as imagens representavam um mesmo espaço, dez estudantes afirmaram que sim, embora não houvesse elementos comuns 
representados nesses espaços. As respostas da maioria indicaram dificuldades no estabelecimento da relação entre tempo e espaço, que são categorias indissociáveis quando se trata do reconhecimento de diferenças e semelhanças. Em relação ao espaço, essas dificuldades sugerem que os estudantes não apresentavam domínio de dimensões espaciais como lateralidade, verticalidade e horizontalidade, que os ajudariam a distinguir elementos representados.

Por outro lado, um estudante tomou como referência uma dimensão mais ampla para identificar o espaço representado como sendo um espaço único: "é o espaço de Jaboatão", enquanto outras sete crianças afirmaram tratar-se de espaços diferentes.

Em relação ao tempo representado, a maioria dos estudantes alegou não se tratar de um mesmo tempo histórico e suas falas revelaram diferentes estratégias para compreensão e justificativa da resposta. Assim, a maioria dos estudantes recorreu às datas apresentadas nas imagens para afirmar que não é o mesmo tempo histórico "porque o ano é diferente" (3 estudantes); "porque as datas são diferentes" (2 estudantes); "porque cada um tem o tempo diferente" (1 estudante); "porque é uma data diferente da outra" (1 estudante) "porque não é da mesma época da outra" (1 estudante). Nas respostas desse grupo o conhecimento referente ao tempo revelou-se vinculado à datação, ou seja, se as datas que representam os anos dos acontecimentos são diferentes, as crianças deduzem que o tempo histórico é também diferente. Nesse caso, a historicidade do tempo estaria sendo reconhecida pelos marcadores temporais expressos nas medidas de tempo, isto é, no ano marcado na identificação da imagem. Nesse sentido, Miranda (2010, p. 371) afirma que:

[...] aquilo que a criança estabelece como parâmetro de entendimento do passado e/ou da mudança assenta-se, muitas vezes, nas relações que se estabelecem entre suas práticas de sociabilidade, os saberes escolarizados, os múltiplos lugares de memória que criam sentidos à moderna experiência o viver no espaço urbano e a indústria cultural que gravita em torno da escola.

Um dos estudantes se utilizou da comparação entre as três datas para declarar que não se trata do mesmo tempo histórico "porque uma é mais nova que a outra" (E-11). Com isso, o estudante estaria talvez se aproximando do 
entendimento de que o tempo é também produtor de mudanças, isto é, o elemento mais novo é diferente do mais antigo, embora não tenha estabelecido nenhuma relação entre as diferenças observadas e as ações sociais nelas presentes. Outro estudante afirmou sem justificar a resposta, que as imagens "não representavam um mesmo tempo histórico" (E-13), no entanto, mesmo sem explicar as razões, utilizou a linguagem do tempo, valendo-se da própria pergunta formulada.

Algumas falas revelaram a emergência da categoria mudança, uma vez que vários estudantes apoiaram suas respostas na observação das mudanças expressas nas imagens e afirmaram não se tratar do mesmo tempo histórico "porque ao longo do tempo tudo mudou" (E-02); "porque mudaram" (E-10); "porque cada imagem representa um tipo de modificação do tempo" (E-12); "porque se passaram várias cenas e mudou" (E-15). Para esse grupo a mudança não estaria referenciada nas datas, mas naquilo que está retratado nas imagens como resultado da ação humana, ou seja, as mudanças são observadas nas várias cenas, na modificação representada na imagem, no continuum do tempo. Para Miranda (2010, p. 372), "o entendimento dessa mudança não se origina, contudo, no interior do espaço escolar e deriva de seu estar no mundo, suas práticas de sociabilidade que são, muitas vezes, anteriores e/ou paralelas à escola".

Com base nas mesmas imagens, os estudantes deveriam responder o que havia de comum entre elas e todos identificaram a sede da prefeitura do município, corroborando a ideia de que as vivências individuais e as práticas de sociabilidade ancoram a compreensão sobre as mudanças, mas também sobre as permanências. As representações da prefeitura foram escolhidas para que os estudantes pudessem formular uma sequência a partir das datas. A maioria dos estudantes demonstrou dificuldades na elaboração da sequência, justificando que "não é possível saber pelas datas que são apresentadas" (E-5); "a imagem 2 é mais velha que a 1 e a 3 não está na ordem correta" (E-2); "as duas primeiras imagens são antigas e a outra é nova" (E-12). Outros três estudantes, embora não tenham ordenado as datas, afirmaram ser possível estabelecer uma sequência "porque cada imagem tem seu tempo". 
Quando perguntados sobre o que é o tempo, a maioria dos estudantes associou o tempo à medida, ao tempo cronológico, relacionando sempre às horas e ao relógio. No entanto, observamos que a compreensão sobre a relação entre passado e presente estaria em processo de construção, pois as crianças recorreram ao relógio para explicar sobre o tempo, mas estariam representando o passado através das expressões: um tempo antigo, grande, muito antigo, coisas que passaram. Assim, para alguns estudantes o tempo "é a medida que eu faço no relógio e o tempo antigo" (E-6); "é um tempo grande, muito antigo". (E-13).

Para outros estudantes, a mudança na paisagem foi a referência para relacionar passado, presente e futuro, como nessas falas: "o tempo passa, mas não para, o tempo vai passando e as coisas vão evoluindo como vemos nas imagens" (E-2); "são as horas, são as coisas que passaram e vão acontecer" (E5); "o que se passa no mundo, e o mundo muda para todos viver" (E-8).

Nessas afirmações os estudantes demonstraram compreensão sobre o tempo cronológico mais imediato e sobre as mudanças que podem ser observadas com referência na relação entre o tempo passado e o tempo presente e até uma sinalização para o futuro como no relato de E-5. Porém, ao identificarem as mudanças, as crianças não apontaram elementos de permanência, a mudança é compreendida como algo linear e que atinge a totalidade dos elementos. De acordo com um dos estudantes, o tempo representa "mudanças do passado para o presente porque mudou tudo" (E-10).

Podemos deduzir das falas analisadas que para compreender a historicidade do tempo o estudante precisa aprender sobre as relações temporais e atribuir sentido ao tempo da ação humana; reconhecer mudanças, mas também permanências; perceber continuidades e rupturas. Contudo, podemos inferir também que parte dessas aprendizagens sobre o tempo foi se construindo em suas vivências cotidianas, na construção de suas próprias histórias. Como no dizer de Miranda (2010), o tempo e o passado se revestem de um alto grau de abstração e sua inteligibilidade só se faz possível no âmbito da duração da nossa vida subjetiva. Para Cainelli (2006, p. 65), "a questão da temporalidade e da forma como as crianças entendem a passagem do tempo está relacionada com a experiência familiar". 
Quando perguntados se o município de Jaboatão dos Guararapes era novo ou antigo, a maioria dos estudantes identificou a cidade do Jaboatão dos Guararapes como uma cidade antiga porque "tem 422 anos" (6 estudantes); "existe há muitos anos atrás" (3 estudantes). "foi descoberta há muito tempo atrás" (E-5); Cinco estudantes compararam o município com o país e responderam que a cidade é nova, porque o Brasil tem "mais anos".

$\mathrm{Na}$ questão que indagava qual o mais antigo, o Brasil ou o município do Jaboatão dos Guararapes a maioria dos estudantes mostrou compreensão, comparou datas e estabeleceu a sequência do que vem antes e depois, ligando sempre as respostas a números, associando tempo e data. Nessa questão percebemos que algumas crianças buscavam apoio em um elemento concreto para reconhecimento da sequência temporal.

A construção da noção de simultaneidade referenciada em acontecimentos da vida cotidiana dos estudantes apontou respostas ancoradas somente em eventos do tempo presente. As crianças relataram atividades vivenciadas em conjunto com membros da família, ou seja, atividades coletivas desenvolvidas ao mesmo tempo, como ir à escola, brincar, comer e tomar banho. Entendemos que as crianças deveriam compreender a historicidade do tempo a partir de sua própria rotina e, nesse sentido, podemos lançar mão de lembranças de comemorações em família, de parentes mais velhos, de fotos de diferentes momentos. Isso porque o tempo está definitivamente ligado à vida humana e quando a criança investiga sua própria história, adquire noção de fatos, espaços e tempos. Para Miranda (2010, p. 372), "é, sobretudo, pela via das práticas de memória a que se encontra submetida no interior desse estar no mundo que a criança estabelece um primeiro sentido a respeito da variável tempo" e uma das fontes primeiras dessas práticas de memória é a família.

Assim, se por um lado a aprendizagem sobre a historicidade do tempo não é tarefa exclusiva da escola por se tratar de um processo iniciado desde muito cedo na vida das crianças e está associada as suas práticas de sociabilidades e as suas memórias, por outro lado, entendemos que a escola e, em especial, o ensino de história tem grande responsabilidade na efetivação desse aprendizado. 


\section{Considerações finais}

Nesta pesquisa buscamos nos aproximar da compreensão que estudantes de uma turma do $5^{\circ}$ ano do ensino fundamental têm a respeito das noções de temporalidade histórica. Dos resultados da investigação emergiram alguns achados sobre os quais consideramos pertinente refletir.

Anotamos inicialmente que, não obstante os indicativos de estudos das últimas décadas sobre o ensino de história nos anos iniciais do ensino fundamental, bem como a concordância em torno da relevância do conceito de tempo para a aprendizagem histórica, nossos resultados corroboram a ideia de que ainda há um longo caminho a ser percorrido pela pesquisa e pela formação docente.

Isso porque nossas análises apontaram que os estudantes compreendem o tempo apoiando-se em sua dimensão cronológica e linear e que a sequenciação de fatos depende da presença de elementos concretos, apresentados de forma ordenada. A construção das noções de simultaneidade estaria circunscrita a acontecimentos da vida cotidiana dos estudantes no tempo presente, não sendo percebida em eventos do passado, e o entendimento sobre a temporalidade histórica estaria em fase inicial de sua construção, em razão da predominância da dimensão cronológica na compreensão da noção de tempo.

Desse modo, entendemos que a diversificação de procedimentos de ensino poderá contribuir significativamente para a consolidação de aprendizagens significativas sobre as noções e relações temporais necessárias à construção do conceito de tempo histórico. Essa diversificação, de outra parte, requer o acesso do estudante a diferentes fontes e linguagens por meio das quais possa refletir sobre diferentes tempos e espaços, expressos em artefatos, brinquedos, vestimentas, adereços, fotografias, vídeos, filmes, músicas, literatura, recortes de notícias, reportagens, entre muitos outros elementos que revelem diferentes modos de vida e comportamentos sociais que deixaram marcas no tempo.

Entendemos ainda que a consciência de viver a história é a chave para a compreensão sobre a historicidade dos acontecimentos e para que os estudantes passem a se sentir autores e coautores de histórias individuais e coletivas que são diversificadas e construídas no decorrer do tempo. 


\section{Referências}

ABUD, Maria José Milharezi. Pedagogia cidadã: cadernos de formação: ensino de história. São Paulo: UNESP, 2004.

BARDIN, Laurence. Análise de conteúdo. Tradução de Luís Antero e Augusto Pinheiro. Lisboa: Edições 70, 1977.

BERGAMASCHI, Maria Aparecida. O tempo histórico no ensino fundamental. In: REUNIÃO ANUAL DA ANPED GT ENSINO FUNDAMENTAL, 23., 2000, Caxambu. Anais [...]. Caxambu: ANPED, 2000.

BRASIL. Ministério da Educação. Secretaria de Educação Fundamental. Parâmetros Curriculares Nacionais: história e geografia: ensino fundamental. Brasília: MEC, 1997.

CAINELLI, Marlene. Educação histórica: perspectivas de aprendizagem da história no ensino fundamental. Educar em Revista, Curitiba, v. 22, p. 57-72, 2006.

CAVALCANTI, Erinaldo. Pernambuco de muitas histórias: história do Estado de Pernambuco. São Paulo: Moderna, [2011].

CONCEIÇÃO, Maria Telvira da. O trabalho em sala de aula com a história e a cultura afrobrasileira no ensino de história. In: OLIVEIRA, M.M.D. História: ensino fundamental. Brasília: Ministério da Educação, 2010. (Coleção Explorando o Ensino, v. 21).

COOPER, Hilary. Aprendendo e ensinando sobre o passado a crianças de três a oito anos. Educar em Revista, Curitiba, p. 171-190, 2006.

CORRÊA, Rosa Lydia Teixeira.. Sobre a permanência de práticas pedagógicas ao longo do tempo histórico. Revista Diálogo Educacional, Curitiba, v. 5, n. 14, p. 111, jan./abr. 2005. Disponível em: www.periodicoscapes.gov.br. Acesso em: 1 abr. 2015.

FONSECA, Selva Guimarães. Didática e prática de ensino de história. Campinas: Papirus, 2003.

FREITAS, Itamar. A experiência indígena no ensino de História. In: OLIVEIRA, M.M.D. História: ensino fundamental. Brasília: Ministério da Educação, 2010. (Coleção Explorando o Ensino, v. 21).

MIRANDA, Sonia Regina. Estranhos passados encontrados em um museu: a criança e seus olhares sobre o tempo desconhecido. Cad. Cedes, Campinas, v. 30, n. 82, p. 369-382, 2010. Disponível em:

http://www.scielo.br/pdf/ccedes/v30n82/07.pdf. Acesso em: 1 abr. 2015. 
NEMI, Ana Lúcia L.; MARTINS, João Carlos. Didática de história: o tempo vivido: uma outra história?. São Paulo: Editora FTD, 1996.

OLIVEIRA, Sandra Regina Ferreira. O tempo, a criança e o ensino de história. In: ZAMBONI, E.; ROSSI, V.L.S. (org.). Quanto tempo o tempo tem!. Campinas: Alínea, 2005.

PERNAMBUCO. Secretaria de Educação. Parâmetros para a educação básica do estado de Pernambuco: história. Recife: Secretaria de Educação, 2013.

RECIFE. Secretaria de Educação. Política de ensino da rede municipal do Recife: ensino fundamental do $1^{\circ}$ ao $9^{\circ}$ ano. Recife: Secretaria de Educação, 2015.

SCALDAFERRI, Dilma Célia Mallard. Concepções de tempo e ensino de história. Londrina. História e ensino, Londrina, v. 14, p. 53-68, ago. 2008. Disponível em: http://www.uel.br/revistas/uel/index.php/histensino/article/viewFile/11522/1022 7. Acesso em: 23 jan. 2015.

SILVA, Marcos Antônio da; FONSECA, Selva Guimarães. Ensino de História hoje: errâncias, conquistas e perdas. Revista Brasileira de História, São Paulo, v. 31, n. 60, p. 13-33, 2010.

SIMAN, Lana Mara de Castro. A temporalidade histórica como categoria central do pensamento histórico: desafios para o ensino e a aprendizagem. In:

ZAMBONI, E.; ROSSI, V. L. S. (org.). Quanto tempo o tempo tem!. Campinas: Alínea, 2005.

VESENTINI, J. Willian; MARTINS Dora; PÉCORA Marlene. Ápis: história $5^{\circ}$ ano. São Paulo: Editora Ática, [2011].

ZAMBONI, Ernesta; FONSECA, Selva Guimarães. Contribuições da literatura infantil para a aprendizagem de noções do tempo histórico: leitura e indagações. Cad. Cedes, Campinas, v. 30, n. 82, p. 339-353, 2010.

ZAMBONI, Ernesta; OLIVEIRA, Sandra Regina Ferreira. O espaço e o tempo no processo de ensinar e aprender história na sala de aula. História Revista, Goiânia, v. 14, n. 1, p. 115-128, 2009.

Recebido em 19 de Agosto de 2018 Aprovado em 02 de Junho de 2020 